\title{
CRITICAL DISCOURSE ANALYSIS ON REPRESENTATION OF RACISM AND SOLIDARITY IN ADIDAS'S TWEETS
}

\author{
Desi Indrawati* \\ Language Center, Computer Science Department, Faculty of Humanities, Bina Nusantara University \\ Bandung Campus, Jl. Kebon Jati No. 218, Bandung, Jawa Barat, 40181, Indonesia \\ desi.indrawati@binus.ac.id
}

Received: $04^{\text {th }}$ March 2021/Revised: $13^{\text {th }}$ June $2021 /$ Accepted: $14^{\text {th }}$ June 2021

How to Cite: Indrawati, D. (2021). Critical discourse analysis on representation of racism and solidarity in Adidas's tweets. Lingua Cultura, 15(1), 109-119. https://doi.org/10.21512/lc.v15i1.7108

\begin{abstract}
The research aimed to analyze how Adidas uses Twitter to convey messages about racism and solidarity in its tweets. Methodologically, the research applied a descriptive qualitative study on the representation of racism in Adidas's tweets involving (1) What are the themes of discourses that represent racism and solidarity in Adidas's tweets? (2) What is the representation of racism and solidarity in Adidas's tweets? and (3) What are the meanings of Adidas's tweets? Twelve tweets from Adidas were collected, coded, analyzed, and described using Critical Discourse Analysis (CDA). It was an effective method for deconstructing the identity of Twitter users to make arguments on the themes exposed during coding. The research findings reveal that the declarative statement and humanitarian as the most themes in Adidas's tweets are the ones that give straightforward and positive messages to Twitter users and followers. The findings also indicate firm and meaningful tweets for Adidas to speak out against racism and spread solidarity through Twitter. However, those tweets also give the messages about their commitment to always supporting the black community, their black employees, the Asian community, and the Black Lives Matter event to embody valuable and eternal change through solidarity, unity, and commitment against racism.
\end{abstract}

Keywords: critical discourse analysis, racism representation, solidarity representation, Adidas, Twitter

\section{INTRODUCTION}

Twitter is a powerful communication platform that allows users to create and share information and ideas in virtual communities and networks. It has allowed brands to build strong relationships with consumers through gradually powerful communication strategies by aiming at consumers' individual and emotional needs, allowing brands to strengthen their connection with their audience. It is also a social networking service that has emerged as a new platform through up-to-date happenings. The public profile includes the full name, the location, a web page, a short biography, and the number of user tweets (Kwak et al., 2010).

The users can participate in the content by liking, commenting, or retweeting the tweets. Additionally, likes permit users to display their positive attitude toward someone's post (Swani et al., 2013). Therewith, Twitter serves as a platform for the media, political actors, and the public to communicate and also serves other users for their communication (McGregor et al.,
2017). It is also a crucial platform since leaders use its analytics to get information (Joseph et al., 2017). Twitter is a prominent source of information and data analysis for various stance analysis practices using machine learning techniques (Khan et al., 2017). However, the significant factor in the application of Twitter is the language that is applied (Michael, 2020). People might be mindful that they should dodge writing tweets that convey stereotype emotionality (Reece et al., 2017).

Majumdar and Bose (2019) have investigated the relationship between Twitter usage and firm value. They find that applying Twitter can have positive leverage on companies' market value. Its importance on social media keeps on to be roamed (Gordon et al., 2019), and social media allow people to share everything (Jackson, 2016). According to Thomas et al. (2018), social media leads an essential role in promoting solidarity.

Kim and Kim (2017) have stated that social media use is certainly connected with youths' communication network diversity that is positively 
connected with social fundamental and subjective prosperity. According to Petray and Collin (2017), social media gives opportunities for discourse about grand issues on a global scale. By contrast, social media usage diminishes real-life social interactions (Berryman, Ferguson, \& Negy, 2018; Hall, Kearney, Xing, 2018). However, Alhabash and Ma (2017) have stated that past research prompted that the competencies and utility of every platform produce specific motivations and gratifications through its use.

Additionally, social interactions rely strongly on the social network framework and allow concerns with ponderable content (Muller \& Peres, 2019). Carlson et al. (2018) have stated that companies get many benefits from social media data to recognize innovation chances and simplify the innovation. They represent the establishment of recent strategic sources that sharpen commerce outputs (Gnizy, 2019).

According to Grieco (2017), most users believe social media is a platform to share and accumulate information. Social media also boosts the continuous transformation of the prevalent mobile screen, specifically among youngsters (Cunningham \& Craig, 2017). While Primack et al. (2017) have found that individuals who use 0 to 2 social media platforms, and individuals who use 7 to 11 social media platforms, have significantly greater chances of having escalated levels of depression signs.

However, social media platforms have come to control socio-political sights in almost every space of the world. Additionally, racist speech progresses on social media, including through political strategies for implementing organizational change (Lamerichs et al., 2018). There have been adequate studies that have proved the existence of racial attacks and hatred towards different races, ethnicities, and religions on the internet (Dubey, 2020). However, this research portrays how a sportswear manufacturing company 'Adidas' voices their veracity against racism that often occurs.

Some studies are pertinent to this research. They are related to the representation of the black community in tweets. Firstly, research about the use of Twitter by black athletes that present their online identities as related to black hypermasculinity (Rinkus, 2012). This research discusses the mainstream media stereotypes black professional athletes as overly aggressive and more masculine than athletes of other ethnicities. Tweets are selected and coded using critical discourse analysis. Finally, the results reveal that those black professional athletes represent more individualized identities.

Secondly, Payne (2007) has found that many blacks seem to evolve their stereotypes. Benner et al. (2018) have stated that the effects of apprehended discrimination might be different based on the time. Blacks in the United States are more solid supporters of affirmative pace and government implementation to look up the status of blacks (Laniyonu, 2018).

The importance of this research is to convey the meaning and values of Adidas's tweets as a sportswear manufacturing company. Tweets can be understood as direct ways for groups of people to talk about various topics, and this research requires a CDA approach to analyze the identity of Twitter users. CDA is most accurately linked with language and the written or oral text, and it challenges the main concept of language (Fiske, 1994). It also allows identification of how power is indicated in the language used and the processes of language reproduces social customs (Mulderrig, Montesano, \& Farrelly, 2019). Moreover, it is a research of how social power misuse, dominance, and inequality are assigned by text and talk in the social context. Some of the principles can be found in critical theory (Van Dijk, 1993).

According to Fairclough (1993), CDA concerns how linguistic forms are used in expressions and power steps. Therefore, it aims to reveal the meaning in the text. The texts from all genres are gained through references from texts, genres, discourses, and individuals (Yunus, Mohamad, \& Waelateh, 2016). CDA also attempts to reveal the sake of the elites and the powerful (Khafaga 2017a, 2017b). Besides, it tries to release light on the manipulative dimension of language that imprescriptible the rhetorical dimension of its power (Khafaga, 2019). Ali, Christopher, and Nordin (2017) have classified the ideological values of CDA.

CDA is a form of discourse analytical research that originally studies the way social power misuse, dominance, and inequality are assigned, reproduced, and refused by text and talk in social and political contexts (Sriwimon \& Zilli, 2017; Gunawan \& Sumarlam, 2018). Yarlott et al. (2018) have said that CDA is a key form of text, giving precious information about the content of a particular gap of the text. According to Drid (2019), Van Dijk's structure for critical discourse analysis depends on two stages of systematic structure. By conducting a CDA approach towards tweets, themes of discourses are determined by finding out the most frequently discussed topics in everyday life (Eriksson $\&$ Kovalainen, 2008). Furthermore, themes are then set in a distinct script and guidance for identification. They are (a) active lifestyle: any tweet indicating or referencing exercise, (b) declarative statement: any tweet with an 'I' statement or statement professing a point or idea, (c) event attendance: any time people attends or references attending a specific happening, (d) expressing excitement: any tweet featuring multiple exclamation points, or words commonly used to express excitement, (e) family and friends: any reference to family or friends. This includes pets when referenced by name, (f) humanitarian: any tweet related to the interests of humankind, (g) introspection: any tweet related to the peoples' emotion, or selfexamination, (h) music: any tweet referencing music or musical artists of any kind, (i) photoshare: any time people tweets a photo, (j) promotion: any tweet referencing a specific brand or product, (k) question: any tweet using a question mark, a rhetorical question, or asking followers for a response, (1) request: any time people asks his followers to 'do' something, including 
'retweet', (m) salutation: any tweet using a greeting, or a valediction (closing), (n) spirituality: any tweet referencing 'god' or 'prayer', or anything related to religion or spirituality, (o) sports: any tweet related to 'sport' of any kind, (p) travel: any tweet where people indicates he is in transit, outside of everyday routine, and (q) world news: any time people tweets about something newsworthy happening inside and outside the US (Eriksson and Kovalainen, 2008). Additionally, some previous studies have appointed a theme or one of the enticing social media, or a different view (Lee \& Watkins, 2016; Safira, Putri, \& Wattimena, 2019; Upadhyay, 2018).

CDA points to the representations of social interactions between the actors. They can be also used for the objectives of being an instigator of action (Van Leeuwen, 2008). Related to the representation of racism in Adidas's tweets is against racism and inequality and for maintaining the existing groups and protecting black people from positions of power and stature in society (Van Dijk, 1998), and a power connection that gets along between individuals in different circumstances (David, 2017).

One of the most recognizing characteristics of CDA as a model of analyzing text and talk is its connection to represent, express, and interpret how discourses develop and approve social inequalities in life (Mullet, 2018). CDA is also an interdisciplinary approach with logical relations between the text and outside the text (Abed, 2018). Additionally, media sources form a typical and main role in communicating the discourse to the readers (Hidayatullah, 2017) and mostly take part to impress and probably change the readers' point of view (Mazumder, 2018). In comparison, Zarrinjooei (2016) has stated that regularly analyzing the texts for investigating the social events and relations on CDA brings the social and linguistic analysis of discourse ( $\mathrm{Su}, 2016)$.

The power of CDA in establishing the reallife overview of minority groups in society cannot be disregarded. It is a crucial part of human viability, and it has cues and embodiments in social life (Rachman, Yunianti, \& Ratnadewi, 2017). While the topics about black people face racism in their lives can be found in texts (Van Dijk, 1998). Meanwhile, the connections between power and domination have always already been identified as a matter (Nonhoff, 2017). CDA is mainly taken to imply studying and taking issue or matter with how power and inequality are augmented through language use (Hussain, Jote, \& Sajid, 2017). CDA is also a social constructivist approach that relies on the representation of the world as linguistic, meanings, and knowledge produced through social interaction (Persada \& Syahrudin, 2018).

The research is associated with Adidas's tweets. Adidas uses Twitter as the platform to promote and update its products and activities. Almost $88 \%$ of companies like Adidas use Twitter for marketing aims (Lister, 2017). They are chosen and perceived to represent racism and solidarity. However, Adidas is founded in 1949 by a German man by the name of Adi
Dassler, in the small German town of Herzogenaurach, Germany, where the company is still headquartered now (Adidas, 2019). Furthermore, the company had begun as a joint venture in 1924 between Adi Dassler and his brother Rudolf. He started his own business that would become the company Puma (Smit, 2006). Since the split, Dassler officially registered the "Adi Dassler Adidas Sportschuhfabrik" in 1949 (Adidas, 2019).

In the research, Adidas's tweets convey thoughts and messages to speak out against racism and spread solidarity. Most of its tweets are addressed to the black community and their Black employees, and it also appears for the Asian community. However, the literature on the value costs of encountering racism proves that Black individuals experience evaluative responses when they face racism or talk about that issue (Czopp \& Monteith, 2003). After all, the racial prejudice and discrimination go through personally and by the black community in general (Anderson \& Hitlin, 2016).

Racism emerges through an inequity intolerance between the majority against a minority. In the United States of America, social discrimination and classification lead to a profound gap between blacks and whites. According to Bowser (2017), racism now portrays factually anything related to racial conflict, for instance, the rejection of the black community in schools as an unprofessional action (Ridgeway \& Yerrick, 2018). Meanwhile, the discourse on inequality is a framing of inequality in terms of both groups taking more advantaged positions (Ray, 2019).

A negative stereotype is being constructed and strengthened to stigmatize people (Lewis, 2020). While, neo-racism is established in white supremacy (Stein \& de Andreotti, 2016; Suspitsyna \& Shalka, 2019). Kwate (2017) has said that concentrating on the health care system disputes that racial differences in life hope are fragmentarily produced. Meanwhile, the current research records that young children between 0 to 8 years old and youth of color in the U.S. deal with negative racial stereotyping from adults (Priest et al., 2018). Also, United States children undergo the negative effects of living in a racialized world (Marcelo \& Yates, 2019).

According to Smedley (2017), racism is any behavior, custom, or belief representing the racial worldview that there is a modest relation between inherited physical characters and characters of identity. By the profound splitting of emerging groups (Ferguson \& Koning, 2018) to the immortal whiteness, race forms officiary achievement in the United States (Gagliardi et al., 2017). The race is not strategically able to refuse of recent circumstances regarding racial inequalities (Mueller, 2017).

According to Mapping Police Violence (2015), African Americans who are armed but do not show an immediate threat towards the police are more potential to be killed than whites, Hispanics, and Asians. Therefore, the black community is possible to undergo more police brutality than whites. These 
experiences are linked to negative health impacts (Alang et al., 2017), and anxiety which negatively sways their mental health (Bor et al., 2018). They are also connected with poverty rates, restricted health care access, and increasingly people with jobs in service industries (Laurencin \& McClinton, 2020; Scott, 2020). Prejudice and discrimination are negatively connected with the adaptive individuals from non-dominant racial groups (Bailey et al., 2017; Samari, 2016). They also stay connected in the lives of individuals from non-majority racial (Bucchianeri et al., 2016; McCord et al., 2018).

Most people progressively notice the format of position hooked to matters of injustice, including current attention to the development and deployment of racism (Lavalley \& Johnson, 2020). While the need of setting the flow of refugees and emphasize that immigrants need to rally wholly into society (Van Sterkenburg, Peeters, \& Van Amsterdam, 2019). Additionally, the anti-social inclination is in which groups of people form a threat to the presence or viability of others (Fafiyebi, 2020).

According to Mohanty (2003), solidarity is also one of the significant parts to end racism. While the conditions, needs, and notions of exemption remain dissimilar (Mayorga \& Picower, 2018). Li (2020) has stated that the more potential the members of nonblack racial and ethnic groups to engage in prevails of cooperation with black activism, the more potential they will strengthen.

Nevertheless, the serious matter of African Americans, slavery is displaced with recent types of racial dominance (Bobo, 2017), and it is significant to put on Black for its political efficacy (Saeed et al., 2019). While Asante, Sekimoto, \& Brown (2016) have said that race, especially blackness, is more than the outside emergence. Besides, they assert that racial identity is developed through symbols, language, culture, and group expertise. Meanwhile, the collections of social, cultural, and moral norms will be adjusted to the instructions that will rely on widely diverse norms (Blommaert, 2019).

The research attempts to counter the following questions, which are (1) what are themes of discourses that represent racism and solidarity in Adidas's tweets? (2) what is the representation of racism and solidarity in Adidas's tweets? and (3) what are the meanings of Adidas's tweets. Furthermore, the research aims to analyze the themes of discourses that represent racism and solidarity in Adidas's tweets and then describe the representation of racism and solidarity in Adidas's tweets and the meaning of its tweets. This research also examines how the Twitter account of the sportswear manufacturing company, Adidas, conveys messages about racism and solidarity to the users.

The research opens the door for further investigation into how Adidas, as the sportswear manufacturing company, shows its integrity against racism through its tweets. Through the use of social media for delivering the messages, the research will focus on the representation of racism and solidarity in Adidas's tweets as they pertained to the Black community and humanity in the social dimension of the text, most particularly the messages that are conveyed in its tweets.

Critical Discourse Analysis (CDA) plays an important role in the research to deconstruct the identity of Adidas's tweets by identifying their themes during coding. It is also the tool to reveal the meanings and messages in Adidas's tweets regarding the black community, their black employees, the Asian community, and the Black Lives Matter event in terms of solidarity, unity, and commitment against racism. Therewith, the research uses CDA that is an analytic method chosen to discover the social processes that reproduce and depict knowledge and power intercourses using discourses (Fairclough, 2003) since it also has obtained popularity in related studies that have been conducted formerly (Al Ghazali, 2017).

Some studies have been taken in several regions based on the Fairclough CDA model (Herdiana et al., 2020). However, CDA is mainly pointed that social representativeness is assigned by discourse (Tampubolon et al., 2017). It also requires critical questions about the part of knowledge in human development and the merger of practical experimentation with theoretical knowledge (Cummings et al., 2018).

\section{METHODS}

The research focuses specifically on how Adidas uses Twitter to convey the public's messages and thoughts. Taking CDA was undertaken on postings from Adidas as a sportswear manufacturing company that supports Black Community and other ethnicities. Therewith, data is collected from a particular starting date, with twelve tweets in concern for the research. CDA is a tool used to disclose implicit meaning, not explicit; "a Critical Discourse Analysis consists of groups of related statements that cohere to produce meanings and effects... a critical discourse produces the 'truth' about objects" that are conversed of (Eriksson \& Kovalainen, 2008). It is also a notion in which the language is identified as a representation that plays a role in forming subjects, themes of certain discourse, and strategies (Ilham \& Darlan, 2017).

Furthermore, the data insert twelve tweets from Adidas's tweets as listed in the sampling. Nevertheless, Adidas has been purposively selected specifically for this research. The research applies a qualitative research with a descriptive method; as Berg (2001) has mentioned that the qualitative research seeks the answer to questions by examining various social and the individuals who inhabit these settings.

Each Tweet in the data is read thoroughly. Then, they are analyzed, and then the themes of the tweets are coded and identified. Finally, they are presented in the table. By applying a CDA on the data, the themes of tweets are specified by delving into what Adidas talks about based on the topics they enter into CDA. 
Those themes of tweets are arranged in a separate document and given instructions for identification. Figure 1 shows the framework of the research.

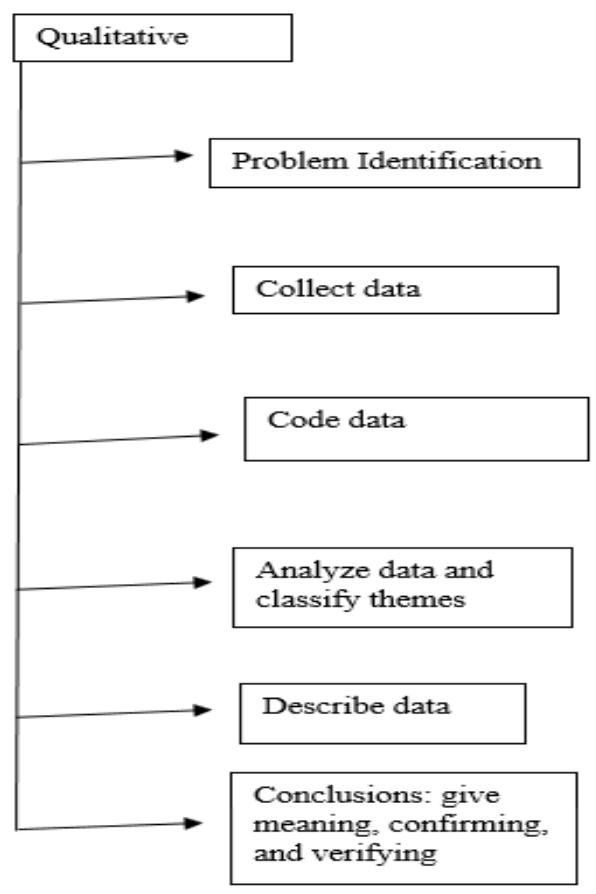

Figure 1 Research Framework

\section{RESULTS AND DISCUSSIONS}

The research findings indicate the representation of racism and solidarity in Adidas's tweets in conveying messages about racism and solidarity to the users and public in general. Undertaking a critical approach, CDA is implemented in Adidas's tweets, with more than one million followers. Data is conducted from a certain date with only twelve tweets from Adidas in deliberation for the research because, during the analysis of Adidas's tweets, only twelve tweets appeared. Those tweets represent solidarity, unity, and commitment against racism. Besides, a CDA is a tool and means used to render implicit and deep meaning not explicit in the discourse. Since the research uses CDA as its method, a profound analysis is demanded from a contextual viewpoint.

After defining the forms of Adidas's tweets based on themes, they are coded to stand cognition of the time-splitting sequent tweets that point to a group. Therefore, there is no limit on the item of themes feasibly present in any given tweet. For each tweet, it is the specified context through citation. This context is to convey a more informed aspect choice when it is not explicitly distinct what Adidas is referencing. Adidas' tweets depict online texts. They are partial, conclusive, and bringing solid images of public assumption through which readers and researchers are lured (Chen et al., 2018). Additionally, Adidas's tweets are analyzed precisely, and they are also presented as factual. The following are coded tweets to identify the themes of discourse that represent racism and solidarity in Adidas' tweets.

First is the tweet on June 11, 2020; "First, we need to give credit where it's long overdue: The success of Adidas would be nothing without Black athletes, Black artists, Black employees, and Black consumers. Period." The themes of the tweet are the declarative statement, event attendance, humanitarian, and world news. Adidas expresses gratitude to black athletes, black artists, black employees, and black consumers who have become part of the company's success. They point out solidarity, support, and humanity towards black people regarding the Black Lives Matter event. Also, this tweet represents solidarity.

Second is the tweet on June 11,2020; "Remaining silent is not a neutral position when the people we should be standing with live in fear of police brutality due to systemic racism. With that in mind, it's our people who we owe this to the most." The themes of the tweet are the declarative statement, event attendance, request, humanitarian, and world news. Adidas speaks out about the truth against racism. Adidas has said that do not just be quiet to show neutrality but must speak out for justice. This tweet is also related to the Black Lives Matter event. Additionally, this tweet represents racism and solidarity.

Third is a tweet on June 11, 2020; "Our black co-workers have shown us through their words and actions what leadership looks like, and the changes Adidas can make. They've led the response that we will continue to implement together. This isn't the final step; this is just the first." The themes of the tweet are the declarative statement, event attendance, family and friends, humanitarian, and world news. Adidas supports their black co-workers' action against racism. They will always work together to speak out about humanity and make the change. The tweet is also related to the Black Lives Matter event. Besides, it represents racism and solidarity.

Fourth is a tweet on June 11, 2020; "This is our commitment to the Black community and the world. We can change, and we will. This is just the start." The themes of the tweet are the declarative statement, event attendance, humanitarian, and world news. Adidas expresses its commitment to support the black community and the world against racism. They also hope to make a change from now and the future. This tweet represents racism and solidarity.

Fifth is the tweet on January 18, 2021; "At Adidas, we are committed to change. On this day of celebration and reflection, we honor the standards set, the legacy that lives on, and the challenge that remains. Read our commitments to creating change at http://adidas.com/lasting_change." The themes of the tweet are the declarative statement, request, salutation, humanitarian, and world news. Adidas states its commitment to change. As a reminder, in June 2020, they share their pledge to give their best in supporting their black employees and black communities by creating meaningful and eternal change first and premier within their brand and further across sport 
culture. They request Twitter users and their followers to read their commitment to creating change at their website. This tweet represents solidarity.

Sixth is the tweet on January 18, 2021; "Today we honor the legacies of those who inspire us to keep dreaming and provide hope for equality." The themes of the tweet are the declarative statement, humanitarian, and photoshare. Adidas appreciates the people who always support them dreaming about now and the future and trust them for solidarity and equality and against discrimination and racism. This tweet is in a media or image form. Additionally, it represents racism and solidarity.

Seventh is the tweet on January 18, 2021; "We are committed to supporting the black community and our employees to create meaningful and lasting change through our united against racism commitments." The themes of the tweet are the declarative statement, family and friends, humanitarian, and photoshare. Adidas states its commitment to always supporting the black community and the employees to embody valuable and eternal change through solidarity, unity, and commitment against racism. This tweet is in a media or image form (Figure 2). Additionally, it represents racism and solidarity.

Eighth is the tweet on January 18, 2021; “Adidas is committed to celebrating and honoring Black excellence all year round." The themes of the tweet are the declarative statement, expressing excitement, humanitarian, and photoshare. Adidas states their commitment to glorify and honor black excellence throughout the year as their support for black people. This tweet is in a media or image form and represents solidarity (Figure 2).

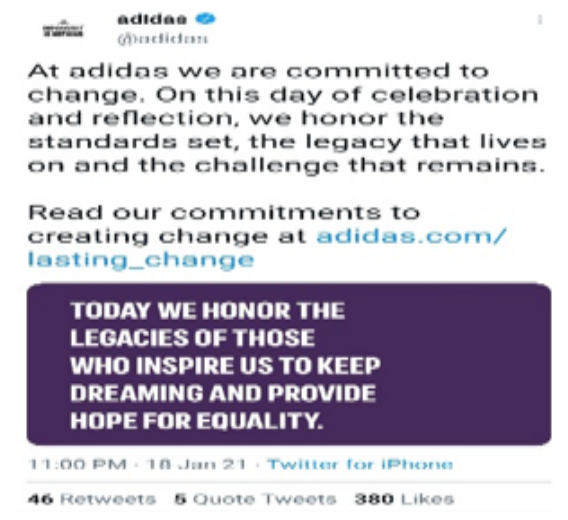

Figure 2 Adidas's Tweets in Image Form

Ninth is the tweet on February 23, 2021; "We stand against racism as one team. You can play your part by sharing helpful resources and info so we can all support each other. STOPASIANHATE." The themes of the tweet are the declarative statement, request, humanitarian, and world news. Adidas invites the Twitter users together against racism and asks them to share anything to support each other. There is a hashtag \#STOPASIANHATE in its tweet that indicates a defense towards the Asian community. This tweet represents racism and solidarity.

The tenth is the tweet on February 24, 2021; "Building a bridge from the past to the future is the marker of black excellence. Here and now, we champion Black resilience, grace, power, and vision for today and tomorrow." The themes of the tweet are the declarative statement, family and friends, humanitarian, salutation, sports, and world news. Adidas provides this tweet as a thread as an honor for black excellent. It states how people get inspired by black community leaders (basketball coach, female athlete, baseball community leaders, Adidas Originals and Bronx native assistant designer, Assistant Product Manager, and North Carolina native) forging a path for the next generation. They greet the Twitter users and convey the message about solidarity and humanity. This tweet represents solidarity.

The eleventh is the tweet on February 24, 2021; "Honoring Black Excellence is our initiative, that celebrates the achievements of Black individuals, and Black culture as a whole. Throughout the year, we'll spotlight honorees by sharing their stories on the platform you've given us." The themes of the tweet are the declarative statement, humanitarian, photoshare, and world news. Adidas states the Twitter users and its followers that honoring black excellence is their initiative for black individuals and black culture as a whole. They also share the names of the recipients of the achievements along with their pictures in their tweets. Additionally, these tweets represent solidarity.

The twelfth is the tweet on February 24, 2021; "This is just the start of celebrating our Black Community. Learn more about Honoring Black Excellence at http://adidas.com/hbe or http://news. adidas.com." The themes of the tweet are the declarative statement, request, salutation, humanitarian, sports, and world news. Adidas closes its thread by stating the beginning of its action to celebrate and support the black community and shares the honoring black excellent site to get the information and news. This tweet represents solidarity. Table 1 shows the themes that appear on those twelve tweets.

Table 1 The Themes in Adidas's Tweets

\begin{tabular}{lc}
\hline \multicolumn{1}{c}{ Themes } & Totals \\
\hline Active Lifestyle & - \\
Declarative Statement & 12 \\
Event Attendance & 4 \\
Expressing Excitement & 1 \\
Family and Friends & 3 \\
Humanitarian & 12 \\
Introspection & - \\
Music & - \\
Photoshare & 4 \\
Promotion & - \\
\hline
\end{tabular}


Table 1 The Themes in Adidas's Tweets (Continued)

\begin{tabular}{lc}
\hline \multicolumn{1}{c}{ Themes } & Totals \\
\hline Question & - \\
Request & 4 \\
Salutation & 3 \\
Spirituality & - \\
Sports & 2 \\
Travel & - \\
World News & 9 \\
\hline
\end{tabular}

The most common themes that represent Adidas's tweets are the declarative statement and humanitarian. Twitter is also established on the principle of sharing thoughts and including them in the conversation (McMillan, 2011). There are twentyfour declarative statements and humanitarian themes in Adidas's tweets after they are classified and coded. The second most frequent theme is the world news theme, and there are nine themes for it. While Event Attendance, Photoshare, and Request, there are totals twelve themes in the tweets. Besides, there are six themes for family and friends and salutation, and two themes appear in the tweets for sports. Lastly, one expressing excitement theme also emerges in the tweet.

Additionally, these themes represent racism and solidarity in Adidas's tweets. Adidas applies Twitter as a front stage for providing the online identity (Rinkus, 2012). Here, Adidas performs its thoughts and messages by showing declarative statements, humanitarian, world news, event attendance, photoshare, request, family and friends, salutation, sports, and expressing excitement.

As a sportswear manufacturing company, Adidas tweets mostly about them to convey the messages and positive thoughts against racism spread the leadership view, solidarity, and humanity to Twitter users and followers, especially to the world. They speak out about how they stand against racism and share helpful resources and info to support each other as solidarity and humanity. Besides, they honor the black community and their black employees. They promise to do better in supporting them by establishing meaningful and eternal change first and principle in their brand and fort over sport culture. Adidas state all of them in its tweets.

Furthermore, a CDA is an effective method to detect themes in Adidas's tweets. As a result of the study for the first research, the question shows that Adidas uses the declarative statement and humanitarian as the most themes. Its tweets give messages about racism and solidarity, as shown in all twelve tweets. Those tweets give straightforward and positive messages to Twitter users and their followers. Adidas's tweets indicate firm and meaningful tweets for Adidas to speak out against racism and spread solidarity through Twitter. Those tweets also convey the messages about Adidas's commitment to always supporting the black community, their black employees, the Asian community, and the Black Lives Matter event to embody valuable and eternal change through solidarity, unity, and commitment against racism.

It is supported by Rinkus's research (2012) that defines the message about racism in tweets always presents the declarative statement. Besides, this research has also analyzed that humanitarian in tweets is also the most common theme, which gives messages about solidarity to end racism.

Van Dijk (1998) has also stated that declarative statements and humanitarian have the concept of power to resist the negative stereotypes of white people, and these themes can represent racism, solidarity, humanity, equality, ethnicity, and many others in texts. While the emersion of CDA is an approach to analyze the themes. Therefore, it creates intent meanings for the interaction with text (Yunira et al., 2019). Furthermore, the discourse of 'given' and 'new' information widens well-formed structures to give information about the topics of interest in linguistics (Kashiwadate et al., 2020).

The research questions demand themes of discourse that represent racism and solidarity in Adidas's tweets, the representation of Adidas's tweets, and the meaning of those tweets. As a result, they communicate racism and solidarity to Twitter users and followers, especially the world. Through their tweets, they also show their support and honor for the black community and their black employees, the Asian community, and the Black Lives Matter event.

Besides, a CDA is applied to discover themes that are presented in Adidas's tweets. In conclusion, Adidas's tweets indicate firm and meaningful tweets for Adidas to speak out against racism and spread solidarity through Twitter.

\section{CONCLUSIONS}

The findings indicate firm and meaningful tweets of Adidas to speak out against racism and spread solidarity through Twitter. However, those tweets also give the messages about their commitment to always supporting the black community, their black employees, the Asian community, and the Black Lives Matter event to embody valuable and eternal change through solidarity, unity, and commitment against racism. Additionally, a profound analysis is established on the twelve tweets to answer research questions regarding racism and solidarity. The most common themes are the declarative statement and humanitarian, which give straightforward and positive messages to Twitter users and followers.

CDA is a fulfilled and effective approach for deconstructing the specialty and identity of Twitter users as long as the researcher is prepared to make arguments on the themes disclosed during coding. Twitter is one of the proper platforms to speak out and convey messages to the world. At last, the research is 
dedicated to future researchers a chance to view what has and has not been performed concerning the online identity display related to CDA through social media.

\section{REFERENCES}

Abed, M. M. (2018). Critical discourse analysis of Oprah Winfrey speech at the 2018 Golden Globe. Qalaai Zanist Scientific Journal, 3(3), 728-746. http:// dx.doi.org/10.25212/lfu.qzj.3.3.31 .

Adidas. (2019). History. Retrieved from https://www. adidas-group.com/en/group/history/.

Alang, S., McAlpine D., McCreedy E., \& Hardeman R. (2017). Police brutality and black health: Setting the agenda for public health scholars. American Journal of Public Health, 107(5), 662-665. https://dx.doi. org/10.2105\%2FAJPH.2017.303691.

Al Ghazali, F. (2017). Awareness of critical discourse analysis underpins learners' sociolinguistic competence and language use. Eurasian Journal of Applied Linguistics. 3(2), 349-366.

Alhabash, S., \& Ma, M. (2017). A tale of four platforms: Motivations and uses of Facebook, Twitter, Instagram, and Snapchat among college students? Social Media + Society, 3(1), 1-13. http://dx.doi. org/10.1177/2056305117691544.

Ali, M. K., Christopher, A. A., \& Nordin, M. Z. F. B. (2017). Pronouns and ideology in newspaper discourse. International Journal of Applied Linguistics and English Literature, 6(3), 168-179. http://dx.doi. org/10.7575/aiac.ijalel.v.6n.3p.168.

Anderson, M., \& Hitlin, P. (2016). Blacks more likely than whites to see and post-race-related content on social media. Retrieved from https://www.pewinternet. org/2016/08/15/blacks-more-likely-than-whites-tosee-andpost-race-related-content-on-social-media/.

Asante, G., Sekimoto, S., \& Brown, C. (2016). Becoming "black": Exploring the racialized experiences of African immigrants in the United States. Howard Journal of Communications. 27(4), 367-384. https:// doi.org/10.1080/10646175.2016.1206047.

Bailey, Z. D., Krieger, N., Agénor, M., Graves, J., Linos, N., \& Bassett, M. T. (2017). Structural racism and health inequities in the USA: Evidence and interventions. The Lancet, 389(10077), 1453-1463. https://doi. org/10.1016/s0140-6736(17)30569-X.

Benner, A.D., Wang, Y., Shen, Y., Boyle, A.E., Polk, R., \& Cheng, Y. P. (2018). Racial/Ethnic discrimination and well-being during adolescence: A meta-analytic review. American Psychologist, 73(7), 855-883 http://dx.doi.org/10.1037/amp0000204.

Berg, B. L. (2001). Qualitative research methods for the social sciences ( $4^{\text {th }}$ Ed.). Boston: Allyn and Bacon.

Berryman, C., Ferguson, C. J., \& Negy, C. (2018). Social media use and mental health among young adults. Psychiatric Quarterly, 89, 307-314. https://doi. org/10.1007/s11126-017-9535-6.

Blommaert, J. (2019). Sociolinguistic restratification in the online-offline nexus: Trump's viral errors. Tilburg Papers in Culture Studies, 234, 1-20.
Bobo, L. (2017). Racism in Trump's America: Reflections on culture, sociology, and the 2016 US presidential election. British Journal of Sociology, 68(1), 85-104. https://doi.org/10.1111/1468-4446.12324.

Bor J., Venkataramani A. S., Williams D. R., \& Tsai A. C. (2018). Police killings and their spillover effects on the mental health of black Americans: A populationbased, quasi-experimental study. Lancet, 2392, 302310. https://doi.org/10.1016/S0140-6736(18)311309.

Bowser, B. (2017). Racism: Origin and theory. Journal of Black Study, 48(6), 572-590. http://dx.doi. org/10.1177/0021934717702135.

Bucchianeri, M. M., Gower, A. L., McMorris, B. J., \& Eisenberg, M. E. (2016). Youth experiences with multiple types of prejudice-based harassment. Journal of Adolescence, 51, 68-75. https://psycnet. apa.org/doi/10.1016/j.adolescence.2016.05.012.

Carlson, J., Rahman, M., Voola, R., \& De Vries, N. (2018). Customer engagement behaviors in social media: Capturing innovation opportunities. Journal of Services Marketing, 32(1), 83-94. https://doi. org/10.1108/JSM-02-2017-0059.

Chen, W. F., Wachsmuth, H., Al Khatib, K., \& Stein, B. (2018). Learning to flip the bias of news headlines. In Proceedings of the 11th International conference on natural language generation. Association for Computational Linguistics. Tilburg University, Netherland. pp 79-88. https://doi. org/10.1177/1461445613490010.

Cummings, S., Regeer, B., de Haan, L., Zweekhorst, M., \& Bunders, J. (2018). Critical discourse analysis of perspectives on knowledge and the knowledge society within the sustainable development goals. LSE Research Online, 36(6), 727-742. https://doi. org/10.1111/dpr.12296.

Cunningham, S., \& Craig, D. (2017). Being "really real" on YouTube: Authenticity, community and brand culture in social media entertainment. Media International Australia, 164(1), 71-81. http://dx.doi. org/10.1177/1329878X17709098.

Czopp, A. M., \& Monteith, M. J. (2003). Confronting prejudice (literally): Reactions to confrontations of racial and gender bias. Personality and Social Psychology Bulletin, 29(4), 532-544. https://doi. org/10.1177/0146167202250923.

David, M. K. (2017). Language, power and manipulation: The use of rhetoric in maintaining political influence. Frontiers of Language and Teaching, 5(1), 164-170. http://dx.doi.org/10.25073/0866-773X/132.

Drid, T. (2019). The study of news: A discourse analysis perspective. Journal El-Bahith in Human and Social Sciences, 10(35), 701-708.

Dubey, A. D. (2020). The resurgence of cyber racism during the COVID-19 pandemic and its aftereffects: Analysis of sentiments and emotions in tweets. JMIR Public Health Surveill, 6(4), e19833. https://doi. org/10.2196/19833.

Eriksson, P., \& Kovalainen, A. (2008). Qualitative methods in business research. California: Sage Publications.

Fafiyebi, D. O. (2020). A critical discourse analysis of 
selected utterances of state actors on the 2019 xenophobic attacks on Nigerians in South Africa. Journal of Language and Literature, 20(2), 199-211. https://doi.org/10.24071/joll.v20i2.2394.

Fairclough, N. (1993). Critical discourse analysis and the commodification of public discourse. Discourse \& Society, 4(2), 133-168.

Fairclough, N. (2003). Analysing discourse: Textual analysis for social research. London: Routledge.

Ferguson, J. P., \& Rembrand, K. (2018). Firm turnover and the return of racial establishment segregation. American Sociological Review, 83(3), 445-474.

Fiske, J. (1994). Media matters: Everyday culture and political change. Minneapolis and London: University of Minnesota Press.

Gagliardi, J. S., Lorelle, L. E., Jonathan, M. T., \& Morgan, T. (2017). American college president study. Washington DC: American Council on Education.

Gnizy, I. (2019). Big data and its strategic path to value in international firms. International Marketing Review, 36(2), 318-341. http://dx.doi.org/10.1108/IMR-092018-0249.

Gordon, B. R., Zettelmeyer, F., Bhargava, N., \& Chapsky, D. (2019). A comparison of approaches to advertising measurement: Evidence from big field experiments at Facebook. Marketing Science, 38(2), 193-225.

Grieco, E. (2017). More Americans are turning to multiple social media sites for news. Retrieved on October 25, 2018 from http://www.pewresearch.org/ facttank/2017/11/02/more-americans-are-turning-tomultiple-social-media-sites-for-news/.

Gunawan, F., \& Sumarlam, S. (2018). The polemic of Kendari beach reclamation on online media (Critical Discourse Analysis). In Proceedings of the International Seminar on Recent Language, Literature, and Local Cultural Studies (BASA 2018). Solo Baru, Indonesia. pp 223-233.

Hall, J. A., Kearney, M. W., \& Xing, C. (2018). Two tests of social displacement through social media use. Information, Communication and Society, 22(10), 1396-1413. https://doi. org/10.1080/1369118X.2018.1430162.

Herdiana, H., Hidayat, D. N., Alek, A., \& Husna, N. (2020). Given and new information in Barrack Obama remarks: A syntactic form of analysis. Journal of Languages and Language Teaching, 8(4), 458-464. https://doi.org/10.33394/jollt.v8i4.2827.

Hidayatullah, M. S. (2017). The khilafah discourse on Aljazeera and Alarabiya: A valuable lesson for Indonesian online media. In International Conference on Culture and Language in Southeast Asia (ICCLAS 2017). Atlantis Press. https://doi. org/10.2991/icclas-17.2018.33.

Hussain, S., Jote, A., \& Sajid, S. (2017). Critical discourse analysis: Demystifying the fuzziness. The International Journal of Humanities \& Social Studies, 3(10), 242-249.

Ilham., \& Darlan, S. (2017). Critical discourse analysis in translation. JETAFL (Journal of English Teaching as a Foreign Language), 3(1), 33-38.

Jackson, S. J. (2016). (Re)imagining intersectional democracy from black feminism to hashtag activism. Women's Studies in Communication, 39(4), 375-379. https://doi.org/10.1080/07491409.2016.1226654.

Joseph, N., Grover, P., Rao, P. K., \& Ilavarasan, P. V. (2017). Deep analyzing public conversations: Insights from Twitter analytics for policy makers. In $16^{\text {th }}$ Conference on e-Business, e-Services and e-Society (I3E). Delhi, India. pp 239-250.

Kashiwadate, K., Yasuda, T., Fujita, K., Kita, S., \& Kobayashi, H. (2020). Syntactic structure influences speech-gesture synchronization. Letters on Evolutionary Behavioral Science, 11(1), 10-14. http://dx.doi.org/10.5178/lebs.2020.73.

Khafaga, A. (2017a). Linguistic manipulation of political myth in Margaret Atwood's The Handmaid's Tale. International Journal of English Linguistics, 7(3), 189-200. https://doi.org/10.5539/ijel.v7n3p189.

Khafaga, A. (2017b). Discourse interpretation: A deconstructive reader-oriented approach to critical discourse analysis. International Journal of Applied Linguistics and English Literature, 6(2), 138-146. https://doi.org/10.7575/aiac.ijalel.v.6n.2p.138.

Khafaga, A. (2019). Linguistic representation of power in Edward Bond's Lear: A lexicopragmatic approach to critical discourse analysis. International Journal of English Linguistics, 9(6), 404-420. https://doi. org/10.5539/ijel.v9n6p404.

Khan, A., Asghar, M. Z., Ahmad, H., Kundi, F. M., \& Ismail, S. (2017). A rule-based sentiment classification framework for health reviews on mobile social media. Journal of Medical Imaging and Health Informatics, 7(6), 1445-1453. http://dx.doi. org/10.1166/jmihi.2017.2208.

Kim, B., \& Kim, Y. (2017). College students' social media use and communication network heterogeneity: Implications for social capital and subjective wellbeing. Computers in Human Behavior, 73, 620-628. https://doi.org/10.1016/j.chb.2017.03.033.

Kwak, H., Lee, C., Park, H., \& Moon, S. (2010). What is Twitter, a social network or a news media? Yuseonggu, Daejeon: Department of Computer Science, KAIST.

Kwate, N. O. A. (2017). The race against time: Lived time, time loss, and black health opportunity. Du Bois Review: Social Science Research on Race, 14(2), 497514. https://doi.org/10.1017/S1742058X17000145.

Lamerichs, N., Nguyen D., Carmen, M., Melguizo, P., Radojevic, R., \& Lange-Böhmer, A. (2018). Elite male bodies: The circulation of alt-right memes and the framing of politicians on social media. Participations, 15(1), 180-206.

Laniyonu, A. (2018). A comparative analysis of black racial group consciousness in the United States and Britain. The Journal of Race, Ethnicity, and Politics, 4(1), 117-147. https://doi.org/10.1017/rep.2018.28.

Laurencin, C. T., \& McClinton, A. (2020). The COVID-19 pandemic: A call to action to identify and address racial and ethnic disparities. Journal of Racial and Ethnic Health Disparities, 7, 398-402. https://dx.doi. org/10.1007\%2Fs40615-020-00756-0.

Lavalley, R., \& Johnson, K. R. (2020). Occupation, 
injustice, and anti-black racism in the United States of America. Journal of Occupational Science, Advance online publication, 1-13. https://doi.org/ 10.1080/14427591.2020.1810111.

Lee, J. E., \& Watkins, B. (2016). YouTube vloggers' influence on consumer luxury brand perceptions and intentions. Journal of Business Research, 69(12), 1-8. https://doi.org/10.1016/j.jbusres.2016.04.171.

Lewis, M. (2020). Criminalizing China. Journal of Criminology Law and Criminology, 111(1), 145-225.

Li, A. (2020). Solidarity: The role of non-black people of color in promoting racial equity. Behavior Analysis in Practice, 14, 549-553. https://doi.org/10.1007/ s40617-020-00498-9.

Lister, M. (2017). 40 essential social media marketing statistics for 2017. Retrieved from http://www. wordstream.com/blog/ws/2017/01/05/social-mediamarketing-statistics.

Majumdar, A., \& Bose, I. (2019). Do tweets create value? A multi-period analysis of Twitter use and content of tweets for manufacturing firms. International Journal of Production Economics, 216, 1-11. https:// doi.org/10.1016/j.ijpe.2019.04.008.

Mapping Police Violence. (2015). Police killed more than 100 unarmed Black people in 2015 (data file). Retrieved from https://mappingpoliceviolence.org/ unarmed/.

Marcelo, A. K., \& Yates, T. M. (2019). Young children's ethnic-racial identity moderates the impact of early discrimination experiences on child behavior problems. Cultural Diversity \& Ethnic Minority Psychology, 25(2), 253-265. https://doi.org/10.1037/ cdp0000220.

Mayorga, E., \& Picower, B. (2018). Active solidarity: Centering the demands and vision of the Black Lives Matter movement in teacher education. Urban Education, 53(2), 212-30. http://dx.doi. org/10.1177/0042085917747117.

Mazumder, N. (2018). Constructing terrorism a critical discourse analysis on the construction of terrorism in Bangladeshi English-Language newspaper editorials. Retrieved from https://www.researchgate. net/publication/331551179_Constructing_ Terrorism_A_Critical_Discourse_Analysis_on_ the_Construction_of_Terrorism_in_Bangladeshi_ English-Language_Newspaper_Editorials.

McCord, M. A., Joseph, D. L., Dhanani, L. Y., \& Beus, J. M. (2018). A meta-analysis of sex and race differences in perceived workplace maltreatment. Journal of Applied Psychology, 103(2), 137-163. https://doi. org/10.1037/ap10000250.

McGregor, S. C., Mourão, R. R., \& Molyneux, L. (2017). Twitter as a tool for and object of political and electoral activity: Considering electoral context and variance among actors. Journal of Information Technology \& Politics, 14(2), 154-167. https://doi.or g/10.1080/19331681.2017.1308289.

McMillan, G. (2011). Why Twitter? Time: Techland. Retrieved from http://techland.time.com/2011/11/17/ whytwitter/2/.

Michael, H. (2020). The use of Twitter by state leaders and its impact on the public during the COVID-19 pandemic. Heliyon, 6(11), e05540. https://doi. org/10.1016/j.heliyon.2020.e05540.

Mohanty, C. T. (2003). Feminism without borders: Decolonizing theory, practicing solidarity. Durham, NC and London: Duke UP.

Mueller, J. C. (2017). Producing colorblindness: Everyday mechanisms of white ignorance. Social Problems, 64(2), 219-238. https://doi.org/10.1093/socpro/ spw061.

Mulderrig, J., Montesano, M. N., \& Farrelly, M. (2019). Critical policy discourse analysis: Advances in critical policy studies series. Cheltenham: Edward Elgar Publishing.

Muller, E., \& Peres, R. (2019). The effect of social networks structure on innovation performance: A review and directions for research. International Journal of Research in Marketing, 36(1), 3-19. https://doi. org/10.1016/j.ijresmar.2018.05.003.

Mullet, D. (2018). A general critical discourse analysis framework for educational research. Journal of Advanced Academics, 29(2), 116-142. https://doi. org/10.1177/1932202X18758260.

Nonhoff, M. (2017). Discourse analysis as critique. Palgrave Communications, 3, 17074. https://doi.org/10.1057/ palcomms.2017.74.

Payne, M. (2007). How does the media portray black America. South Carolina: Helium.

Persada, I., \& Syahrudin, J. (2018). A critical discourse analysis of Indonesia presidential election in 2014 giving speeches in campaign debate. E-Journal of English Language and Literature, 7(3), 1-20.

Petray, T. L., \& Collin, R. (2017). Your privilege is trending: Confronting whiteness on social media. Social Media + Society, 3(2), 1-10. https://doi. org/10.1177/2056305117706783.

Priest, N., Slopen, N., Woolford, S., Philip, J. T., Singer, D., Kauffman, A. D., Moseley, K., Davis, M., Ransome, Y., \& Williams, D. R. (2018). Stereotyping across intersections of race and age: Racial stereotyping among white adults working with children. PLoS One, 13(9), e0205614. https://doi.org/10.1371/ journal.pone.0205614.

Primack, B. A., Shensa, A., Escobar-Viera, C. G., Barrett, E. L., Sidani, J. E., Colditz, J. B., \& James, A. E. (2017). Use of multiple social media platforms and symptoms of depression and anxiety: A nationallyrepresentative study among U.S. young adults. Computers in Human Behavior, 69, 1-9. https://doi. org/10.1016/j.chb.2016.11.013.

Rachman, A., Yunianti, S., \& Ratnadewi, D. (2017). Critical discourse analysis in Donald Trump presidential campaign to win Americans' heart. TELL Journal, 5(2), 8-17. http://dx.doi.org/10.30651/tell.v5i2.388.

Ray, V. (2019). A theory of racialized organizations. American Sociological Review, 84, 26-52. https:// doi.org/10.1177/0003122418822335.

Reece, A. G., Reagan, A. J., Lix, K. L. M., Dodds, P. S., Danforth, C. M., \& Langer, E. J. (2017). Forecasting the onset and course of mental illness with Twitter data. Scientific Reports, 7(1), 1-11. https://doi. 
org/10.1038/s41598-017-12961-9.

Ridgeway, M. L., \& Yerrick, R. K. (2018). Whose banner are we waving? Exploring STEM partnerships for marginalized urban youth. Cultural Studies of Science Education, 13(1), 59-84. https://doi. org/10.1007/s11422-016-9773-1.

Rinkus, B. E. ( 2012). Analysis of Twitter usage by select black professional athletes presenting their online identities, as related to black hypermasculinity. Washington: School of Professional Studies Gonzaga University.

Saeed, A., Rae, E., Neil, R., Connell-Hall, V., \& Munro, F. (2019). To BAME or not to BAME: The problem with racial terminology in the civil service. Retrieved from https://www.civilserviceworld.com/articles/opinion/ bame-or-not-bame-problem-racialterminology-civilservice.

Safira, A., Putri, D. W., \& Wattimena, G. H. (2019). Self presentation beauty influencer Abel Cantika via Youtube. Profetik Jurnal Komunikasi, 12(1), 30-45. https://doi.org/10.14421/pjk.v12i1.1583.

Samari, G. (2016). Islamophobia and public health in the United States. American Journal of Public Health, 106(11), 1920-1925. https://doi.org/10.2105/ AJPH.2016.30337.

Scott, E. (2020). 4 reasons coronavirus is hitting black communities so hard. Retrieved from https://www. washingtonpost.com/politics/2020/04/10/4-reasonscoronavirus-is-hitting-black-communities-so-hard/.

Smedley, A. (2018). Racism. Edinburgh: Encyclopedia Britannica.

Smit, B. (2006). Pitch invasion: Three stripes, two brothers, one feud: Adidas, Puma, and the making of modern sport. London, New York: Allen Lane.

Sriwimon, L., \& Zilli, P. J. (2017). Applying critical discourse analysis as a conceptual framework for investigating gender stereotypes in political media discourse. Kasetsart Journal of Social Sciences, 38(2), 136142. https://doi.org/10.1016/j.kjss.2016.04.004.

Stein, S., \& de Andreotti, V. O. (2016). Cash, competition, or charity: International students and the global imaginary. Higher Education, 72(2), 225-239. https://doi.org/10.1007/s10734-015-9949-8.

$\mathrm{Su}, \mathrm{T}$. (2016). Positive discourse analysis of Xi Jinping's speech at the National University of Singapore under appraisal theory. Journal of Language Teaching and Research, 7(4), 796-801. http://dx.doi.org/10.17507/ jltr.0704.22.

Suspitsyna, T., \& Shalka, T. R. (2019). The Chinese international student as a (post) colonial other: An analysis of cultural representations of a US media discourse. The Review of Higher Education, 42(5), 287-308. https://doi.org/10.1353/rhe.2019.0053.
Swani, K., Milne, G., Cromer, C., \& Brown, B. P. (2013). Fortune 500 companies' use of Twitter communications: A comparison between product and service Tweets. International Journal of Integrated Marketing Communications, 5(2), 47-56.

Tampubolon, S., Saragih, A., Setia, E., \& Nurlela. (2017). Critical discourse analysis on Medan local newspapers' editorial. International Journal of Linguistics, 9(2), 139-147. http://dx.doi.org/10.5296/ ijl.v9i2.10792.

Thomas, E. F., Cary, N., Smith, L. G. E, Spears, R., \& McGarty, C. (2018). The role of social media in shaping solidarity and compassion fade: How the death of a child turned apathy into action but distress took away. New Media \& Society, 20(10), 37783798. https://doi.org/10.1177/1461444818760819.

Upadhyay, S. (2018). A conceptual model incorporating Twitter as a language tool in ESL/EFL learning. TESOL International Journal, 13(4), 49-54.

Van Dijk, T. A. (1993). Principles of critical discourse analysis. Discourse \& Society, 4, 249-283. https:// doi.org/10.1177/0957926593004002006.

Van Dijk, T. A. (1998). Ideology. London: Sage

Van Leeuwen, T. (2008). Discourse and practice: New tools for critical discourse analysis. New York: Oxford University Press.

Van Sterkenburg, J., Peeters, R., \& Van Amsterdam, N. (2019). Everyday racism and constructions of racial/ethnic difference in and through football talk. European Journal of Cultural Studies, 22(2), 136754941882305. https://doi. org/10.1177/1367549418823057.

Yarlott, W. V. H., Cornelio, C., Gao, T., \& Finlayson, M. A. (2018). Identifying the discourse function of news article paragraphs. In Proceedings of the workshop on events and stories in the news. New Mexico, USA. pp 25-33.

Yunira, S., Pradina, S., Sumbayak, M., Putri, N. S., \& Derin, T. (2019). Re-visits the grand theory of Geoffrey Leech: Seven types of meaning. REiLA: Journal of Research and Innovation in Language, 1(3), 95-100. https://doi.org/10.31849/reila.v1i3.3768.

Yunus, K., Mohamad, M., \& Waelateh, B. (2016). The breadth of receptive vocabulary knowledge among English major university students. Journal of Nusantara Studies, 1(1), 7-17. http://dx.doi. org/10.24200/jonus.volliss1pp7-17.

Zarrinjooei, N. (2016). Reproducing the institutional discourses: A critical language awareness approach. International Journal for $21^{\text {st }}$ Century Education, 3(1), 77-84. http://dx.doi.org/10.21071/ij21ce. v3i1.5649. 